\title{
Understanding and Reducing Biases in Elite Beliefs About the Electorate
}

\author{
MIGUEL M. PEREIRA University of Southern California
}

\begin{abstract}
$T$ o be responsive, politicians have to rely on beliefs about public will. Previous research suggests that perceptions of public opinion are often distorted. However, it remains unclear (1) why reelectionseeking officials misperceive public preferences and (2) how to mitigate these distorted beliefs. I argue that misperceptions result from unequal exposure to different subconstituencies and a tendency of legislators to project their own preferences on voters. I find support for these arguments in a six-wave panel of Swedish MPs combined with mass surveys. Elite beliefs disproportionately reflect the preferences of privileged voters and the personal positions of legislators. Additionally, an experiment with Swiss representatives leveraging real political events reveals how misperceptions can be reduced by encouraging a more balanced exposure to voters. The study concludes that economic and political inequalities are rooted in elite beliefs about the electorate and reveals ways to bolster the links between voters and their representatives.
\end{abstract}

H ow do politicians learn about public preferences? Office-seeking officials have incentives to be informed (Downs 1957; Geer 1996; Pereira 2020). However, a growing literature suggests that learning about what voters want is more demanding than originally suggested (Butler and Nickerson 2011; Druckman and Jacobs 2015). Representatives often have a distorted image of their constituents (Broockman and Skovron 2018; Converse and Pierce 1986; Erikson, Luttbeg, and Holloway 1975; Holmberg 1989; Kertzer et al. 2020; Miller and Stokes 1963). Therefore, a key ingredient for policy responsiveness is frequently missing. This leads to two crucial questions that I explore in this article: (1) why do politicians misperceive public preferences and (2) how can misperceptions be mitigated?

I explore two factors that may lead political elites to misperceive constituency preferences: inequalities in exposure and personal biases of legislators. First, representatives do not interact with all subconstituencies in the same way. More affluent and organized groups are more likely to make their voices heard in the policymaking process (e.g., Gallego 2007; Schlozman, Verba, and Brady 2012). ${ }^{1}$ This differential exposure to moreprivileged subconstituencies can lead officials to rely disproportionately on these voices when forming opinions about public preferences. In short, inequalities in political resources across voters can generate distorted images of the constituency. Furthermore, legislators' own personal background can also influence exposure.

Miguel M. Pereira (D), Assistant Professor, Department of Political Science and International Relations, University of Southern California,m.pereira@usc.edu.

Received: April 22, 2020; revised: February 21, 2021; accepted: April 23, 2021. First published online: June 08, 2021.

\footnotetext{
${ }^{1}$ I use the terms "high-status voters," and "privileged voters" interchangeably to describe segments of the electorate with more political resources.
}

Policy makers are drawn disproportionately from more affluent segments of the electorate (Carnes and Lupu 2015), and the social networks of public officials can shape their image of the constituency (Campbell 2013). Taken together, these arguments suggest that misperceptions can result from the type of information that is more accessible to politicians.

However, unequal exposure only tells part of the story. Personal biases of elected officials may also distort perceptions of public opinion. Representatives may be inclined to engage in social projection: projecting their own policy preferences on voters (Krueger and Clement 1994). This cognitive bias may lead representatives to overestimate support for policies they themselves endorse. Social projection may result from a systematic tendency of public officials to deem opposing views as uninformed or nonsalient (Butler and Dynes 2016). Hence, even without inequalities in political voice, politicians may generate images of the constituency that are tinted by their own views.

I test these expectations with surveys of elected officials in Sweden and Switzerland. Study 1 explores a six-wave panel of Swedish MPs covering two decades of elite beliefs about voters. This dataset was combined with mass surveys fielded concurrently to create measures of perceptual accuracy for 24 policy issues. The analyses reveal that elite beliefs disproportionately reflect the preferences of high-status voters. On average, the probability of an MP correctly perceiving the majority opinion on a given policy issue decreases 12 points when white-collar voters disagree with the median voter in a given party. Consistent with the mechanisms proposed, these effects are moderated by the types of groups MPs interact with-unions or business organizations - and by the personal background of legislators. The analyses also show evidence of social projection: elected officials systematically overestimate support for policies they personally endorse.

Study 2 was designed to explore whether the biases uncovered in the first study can be mitigated. In an 
original experiment that leveraged real political events, 2,917 Swiss local elected officials were asked to estimate support for two upcoming referendums in their constituencies. Together with the disaggregated results from the popular votes, these data allowed me to produce precise measures of perceptual accuracy at the local level. Officials were randomly assigned to informational cues designed to overcome inequalities in exposure and social projection. The probability of representatives correctly predicting majority preferences in their constituency increased 4 to 9 percentage points when encouraged to avoid availability heuristics and consider the electorate more broadly. Encouraging officials to avoid social projection, in turn, reduced the tendency to overstimate support for policies endorsed, as expected, but this effect did not improve the ability of representatives to identity the majority opinion.

The patterns uncovered here are consistent with recent scholarship in the United States showing that political elites systematically perceive their own constituents as more conservative than they actually are (Broockman and Skovron 2018; Hertel-Fernandez, Mildenberger, and Stokes 2019). This conservative bias in elite beliefs can be partially explained by inequalities in political voice, as more affluent voters in the United States tend to be more conservative (Mendelberg, McCabe, and Thal 2017; Suhay, Klašnja, and Rivero 2021).

The study sheds light on the constraints faced by elected officials to act on behalf of those who elected them (Butler and Nickerson 2011; Pitkin 1967). The findings contribute to scholarship on political representation and elite behavior. Prior work established that affluent voters have an easier time converting preferences into policy in Sweden (Persson and Branham 2020), Switzerland (Lloren, Rosset, and Wüest 2015), and elsewhere (Adams and Ezrow 2009; Bartels 2008; Giger, Rosset, and Bernauer 2012; Homola 2019; Gilens 2009; Schakel 2019). The patterns uncovered here suggest that unequal exposure to voters can partially explain these dynamics, by producing distorted beliefs about public preferences. Thus, policy outputs can reproduce existing inequalities even when legislators are not trying to favor any particular subconstituency.

\section{THE NATURE OF ELITE PERCEPTIONS OF PUBLIC OPINION}

Aggregating preferences is intrinsically complex. Timeconstrained politicians are exposed to a vast array of cues available through different channels: direct contacts from constituents, lobbyists, the media, social networks, political parties, or peers. To condense these overlapping demands is a daunting task, and the information available to legislators is often incomplete (Butler and Nickerson 2011; Gulzar, Haai, and Paudel 2020; Pereira 2019). This context offers fertile ground for the adoption of cognitive shortcuts. Individuals rarely conduct extensive information searches before making judgments, particularly for complex decisions (Tversky and Kahneman 1974). Instead, they rely on a subset of available information. More accessible information is more easily retrieved from memory and therefore tends to play a dominant role in individual judgments (Ajzen 1996; Carlston and Smith 1996). However, heuristics have limits. The subset of information on which individuals rely may not be representative of all the information available (Fiedler and Schmid 1995; Lodge, Stroh, and Wahlke 1990).

I argue that (1) inequalities in exposure to voters and (2) the policy preferences of legislators shape the type of information that becomes available to public officials. When this subset of information is biased, it may translate into misperceptions. Information availability, in this context, refers to the "ease with which instances and occurences could be brought to mind" (Tversky and Kahneman 1974, 15). The two arguments articulated below are expected to play a central but not exclusive role in explaining misperceptions. Complementary explanations are discussed in the concluding section.

Before moving forward, I should clarify the concept of constituency adopted in the study. Constituency is defined as the group of subjects who grants authority and holds accountable an elected official or party (Rehfeld 2005). From the legislators' perspective, it refers to any representation of the public that acts as principal in the delegation chain. Therefore, a constituency can take different shapes depending on the institutional context in which legislators operate. Common conceptualizations include geographical constituencies, party constituencies, or the electorate as a whole (Däubler 2020; Esaiasson and Holmberg 1996; Katz 2020). ${ }^{2}$ Some explanations for why legislators misperceive constituency preferences may vary according to the way a constituency is defined. However, as articulated below, I expect both sources of misperceptions proposed here to apply to different representations of the public.

\section{Exposure and Beliefs}

Elected officials do not interact with all segments of their constituency in the same way. Systemic inequalities in political resources between subgroups, as well as legislators' own personal networks, shape the type of information that is more readily available.

A cross-cutting pattern in contemporary democracies is that more affluent (Gallego 2007; Schlozman, Verba, and Brady 2012; Verba, Schlozman, and Brady 1995), organized (Klüver 2020; Olson 1965; Schattschneider 1975), politically engaged (Galston 2001; Griffin and Newman 2005), and well-connected (Campbell 2013) segments of society are more likely to make their voices heard in the policy-making process. Hence, the preferences of privileged subconstituencies are often more salient in the public discourse. If officials rely on

\footnotetext{
${ }^{2}$ As Richard Katz (2020) puts it, "[i]n a democracy, the represented naturally are primarily the citizens but they can be classified in many ways $[\ldots]$. Significantly, however, the particular aggregate represented in the expressive sense need not be the same, or even at the same level of aggregation, as that represented in the governing sense" (258).
} 
availability heuristics to gauge public preferences-as posited above - the positions of high-status voters may be given disproportionate consideration. There is some evidence for this argument in the American context. When Congressional staffers think about subconstituencies relevant for a given policy initiative, they are more likely to recall groups that often contact and contribute to the legislator (Miler 2007).

Interest groups also shape whose opinions become more readily available to legislators (Klüver 2020). There is ample evidence of representational biases in the pressure system (e.g., Binderkrantz, Christiansen, and Pedersen 2015; Crosson, Furnas, and Lorenz 2020). Even in organizations that represent marginalized subconstituencies, the preferences of their most advantaged members tend to prevail. Groups representing low-income people or racial minorities are substantially less active on issues affecting disadvantaged members (Strolovitch 2008). Therefore, I expect interest groups to reproduce and amplify existing inequalities in political voice.

Information gathered through legislators' personal experience is also more accessible. Familiar information is easier to recall (Tversky and Kahneman 1974). Reviewing his experience in office, a former mayor from a suburb of Washington, DC illustrates this challenge: "both [factions in the legislature] may have wrongly estimated the location of the median voter-it is easy to do when one regularly receives vocal communications from your neighbors $[\ldots]$ on the street and in your inbox" (Lublin 2018, 171). More broadly, researchers have noticed for decades that our social networks tint our image of the world: our political attitudes and behavior (Campbell 2013). At the same time, in most countries policy makers are drawn disproportionately from more privileged segments of society (e.g., Carnes and Lupu 2015). If representatives use availability heuristics to gauge constituency preferences, as proposed here, they may rely disproportionately on the positions of these same privileged subconstituencies.

Together, both mechanisms suggest that the preferences of high-status voters are more visible to legislators. When the policy positions of privileged subconstituencies are aligned with the majority, inequalities in exposure are not expected to distort perceptions of public opinion. However, when in disagreement, unequal exposure combined with availability heuristics can lead to misperceptions. Importantly, this process may take place unconsciously. It does not require any active discrimination from legislators (Butler 2014). The following implication derives from these arguments:

Exposure Hypothesis: Elected officials are more likely to misperceive public opinion when high-status voters disagree with the majority.

\section{Personal Preferences and Beliefs}

Differential exposure is not the only source of misperceptions. Even when public opinion information is not skewed, personal biases may distort how elected officials process and incorporate constituency signals.
Gauging constituency preferences is a social inference task. A potential bias associated with this cognitive process is known as social projection (or false consensus bias): the propensity to overestimate the degree to which others share our attitudes and beliefs (Ross, Greene, and House 1977). Social projection is one of the most robust and well-documented social judgment biases (Mullen et al. 1985). Nearly a century ago, Katz and Allport (1931) found that students who cheated in tests systematically overestimated the share of peers who had also cheated. The tendency to project our attitudes on others is moderated by perceptions of similarity (Davis 2017) and is understood as an irrational and unavoidable behavior rather than a result of statistical (i.e., Bayesian) reasoning (Krueger and Clement 1994). However, recent scholarship suggests that social projection can be mitigated through incentives (Epley et al. 2004) or personalized feedback (Morewedge et al. 2015).

Among political elites, there is a large amount of anecdotal evidence suggesting that representatives engage in this type of bias. In recent years, David Cameron's decision to call a referendum on the United Kingdom's membership in the European Union is one of the most consequential episodes resulting, in part, from false consensus bias. The British prime minister campaigned against Brexit. However, as analysts described at the time, "David Cameron underestimated the strength of Eurosceptic feeling and probably also the discredit of which his government [was] the focus" (The Robert Schuman Foundation 2016, 6). Early scholarship on elite beliefs provides suggestive evidence in line with this view (Converse and Pierce 1986; Holmberg 1974; see also Hertel-Fernandez, Mildenberger, and Stokes 2019). Based on a survey of members of the European Parliament, Holmberg (1999) concluded that " $[\mathrm{t}]$ he unpleasant truth is that a largely irrational tendency toward wishful thinking is more significant for members' knowledge of voter opinion than other more rational processes of knowledge acquisition" (249). These behavioral patterns may be due to a tendency of public officials to discount opinions they disagree with (Butler and Dynes 2016). Contrasting views are systematically seen as less informed and less likely to represent the majority opinion. Hence, social projection can translate into misperceptions by altering the type of information that is most visible (or available) to legislators. These arguments suggest the following prediction:

Social Projection Hypothesis: Elected officials are more likely to misperceive public opinion when disagreeing with the majority position on a given policy issue.

As the term "projection" implies, the argument suggests that legislators' attitudes inform their beliefs about constituency preferences. There is robust causal evidence of this cognitive bias in different contexts: individuals randomly assigned to a state (an experience, opinion, or behavior), overestimate the prevalence of that state (e.g., Agostinelli et al. 1992; Krueger and Clement 1994; van Boven, Dunning, and Loewenstein 2000). At the same 
time, perceptions about others can also shape preferences, particularly when individuals hold weak or ambiguous attitudes. In the context of politicians' beliefs about voters, I expect this alternative causal pathway to play a limited role. First, self-referent information (e.g., our personal preferences) is more accessible than estimates about the attitudes and behavior of others (Clement and Krueger 2000). Second, by the nature of their job, policy makers are more likely to hold policy preferences rooted in information and less susceptible to change. (Christensen and Moynihan 2020). Finally, politicians often see themselves as opinion leaders and engage in efforts to shape public opinion rather than accommodating it (Gabel and Scheve 2007; Page and Shapiro 1984).

\section{The Relationship between Exposure and Social Projection}

Exposure and issue preferences are not independent from each other. Exposure can either influence or be influenced by the personal positions of legislators. Additionally, descriptive representation - to the extent that it shapes both the type of constituents with which legislators interact and the policies they most care about - can influence both arguments. That said, the arguments advanced above should have independent (unmediated) effects on perceptions of public opinion. The empirical strategy adopted in this study was designed to isolate these different dynamics.

To illustrate these differences, it is useful to consider how political inequality relates to each theoretical argument. According to the exposure hypothesis, inequalities in political resources produce distorted beliefs independent of the personal preferences of the legislator. On the other hand, according to the projection hypothesis, elite beliefs only reflect political inequalities if the preferences of legislators are aligned with the position of more-privileged subconstituencies (and not aligned with the majority opinion). Therefore, although exposure and projection may affect each other, I expect both arguments to have independent effects on the ability of legislators to gauge constituency preferences.

\section{EMPIRICAL STRATEGY}

I test the main predictions derived from the theory in two complementary studies. Both studies conceptualize perceptual accuracy as the ability of political elites to correctly identify the majority position on a given issue (Pitkin 1967). Study 1 is based on a long-running panel of Swedish MPs matched with two mass surveys fielded concurrently for over two decades. To my knowledge, these data sources represent the most comprehensive effort to measure elite perceptions of public opinion. The analyses in Study 1 are designed to investigate the two main predictions derived from the theory and the mechanism underlying the exposure hypothesis.

Study 2 complements the first study through an original survey with Swiss local elected officials. I designed this study to explore whether inequalities in exposure and social projection can be experimentally manipulated. Days before two federal referendums, politicians were asked to estimate the share of voters in their municipality supporting each initiative on the ballot. Prior to this task, politicians were randomly assigned to informational nudges designed to induce perceptual accuracy by avoiding unequal exposure and social projection. This empirical strategy allows me to assess the extent to which biases in elite perceptions of public opinion can be mitigated.

Relying on two of the wealthiest countries in the world restricts the scope of the findings. Relative to the average elected official in Europe, Swedish and Swiss legislators may have more resources to gauge public preferences. However, both countries are also among the most socially inclusive societies in the world, making them hard cases to uncover the political consequences of inequalities in political voice. ${ }^{3}$ The gaps in preferences between privileged subconstituencies and the majority tend to be starker in contexts with more income inequality (Rueda and Stegmueller 2016; Voorheis, McCarty, and Shor 2015). Additionally, to the extent that descriptive representation can mitigate inequalities in exposure, Sweden stands out as one of the countries where MPs (relatively) better reflect the social diversity of their constituency. Scandinavian parliaments are among the most broadly based legislatures (Esaiasson and Holmberg 1996; Norris and Levendusky 1995; but see Dal Bó et al. 2019). Two features of the Swiss system may also mitigate informational asymmetries. First, the frequency of referendums and other direct democracy instruments provides regular data on voter preferences to policy makers. Second, local Swiss legislators in Study 2 are largely part-time politicians who maintain an active role in civil society, potentially facilitating exposure to different subconstituencies. For these reasons, Sweden and Switzerland represent less likely cases by which to identify the effects of informational asymmetries. ${ }^{4}$

Sweden and Switzerland have relatively influential political parties, and the decisions of individual legislators in both countries may be constrained by intraparty dynamics (Giger and Klüver 2016; Öhberg and Naurin 2016). ${ }^{5}$ However, distorted beliefs about the electorate are consequential regardless of how partycentric a system is. Political parties are groups of individuals. If these individuals express similar types of biases when gauging public opinion, these biases should carry on to the collective decisions of parties. Appendices A and D provide more contextual information about Sweden and Switzerland, respectively.

\footnotetext{
${ }^{3}$ According to the Social Progress Index (www.socialprogress.org) Sweden and Switzerland are globally ranked 11 th and 3rd, respectively, regarding basic human needs, foundations of well-being, and individual opportunity.

${ }^{4}$ Recent evidence from Pakistan is consistent with this perspective. In a survey of Pakistani local officials, only $59 \%$ of representatives correctly perceived the majority opinion in their constituency (Liaqat 2020). The equivalent figures for Sweden and Switzerland, as described below, are around $70 \%$.

${ }^{5}$ This is less of an issue in the Swiss context, where candidates for local office often run without a party label (Ladner 2005).
} 


\section{STUDY 1: PANEL OF SWEDISH LEGISLATORS}

To measure elite perceptions of public opinion, I first rely on a constellation of survey data from Sweden. Since 1985, the Swedish Parliamentary Survey (RDU) has surveyed MPs once every term. For each wave of the RDU, response rates have been consistently above $90 \%$. ${ }^{6}$ The panel asks elected officials their own opinions on a large set of policy issues, along with perceptions of constituency preferences on those same issues. For six waves of the parliamentary survey $-1985,1988$, 1994, 1998, 2002, and 2006-the Swedish National Election Studies (SNES) and the SOM Institute Surveys (SOM) asked identical policy questions to representative samples of voters in the same period.

In order to compare elite perceptions with voters' expressed policy preferences, I combined all three datasets. Whenever the SNES and SOM conducted mass surveys concurrently, I merged the two samples. On average, the combined dataset includes 4,865 respondents per wave. ${ }^{7}$ With these data, I calculated different measures of policy support, as detailed below. Overall, 24 distinct policy issues were asked simultaneously in the MP and mass surveys. Additionally, on average each of the policy items was asked in three of the six matched waves. Table B1 lists all policy issues, waves, and sources used in the analysis. Since the key goal of Study 1 is to explain individual variation in the ability of legislators to gauge public preferences, the unit of analysis is MP-yearpolicy. The combined dataset includes 22,373 individual perceptions of voter preferences.

\section{Measuring Perceptual Accuracy}

The main outcome of interest in Study 1 is a measure of perceptual accuracy. Respondents in the mass surveys were given a five-point Likert scale to answer each policy support question. In turn, MPs were asked whether a majority of their "own party's voters" supported a given policy. In the Swedish context, the party base is considered the most relevant constituency for representatives (Esaiasson and Holmberg 1996). ${ }^{8}$ To

\footnotetext{
${ }^{6}$ In the six waves used in the current study, response rates were $97 \%$ (1985 and 1994), 96\% (1988), and 94\% (1998, 2002, and 2006) (Karlsson and Nordin 2015). Given the nearly complete coverage of the survey, full access to the datasets is restricted to the precincts of the University of Gothenburg.

${ }^{7}$ Combined sample sizes by wave: 4,365 respondents in $1985,4,135$ in 1988, 3,996 in 1994, 5,340 in 1998, 6,184 in 2002, and 5,170 in 2006.

${ }^{8}$ This pattern is not specific to party-centric systems. Lax, Phillips, and Zelizer (2019) recently uncovered similar dynamics in the American context. In the United States, members of Congress mainly respond to the preferences of their own party constituency. Still, to assess the sensitivity of the findings to this type of constituency, I replicated the main analyses with perceptions of the electorate as a whole (and not just the party constituency). These items are only available in the 1985 wave of the parliamentary survey. Besides the loss in scope, the same results are obtained (Table C4). Additionally, I extended the analyses from Hertel-Fernandez, Mildenberger, and Stokes (2019) to provide an out-of-sample test of the same hypotheses using the electorate as the reference constituency. The analysis reported in Appendix $\mathrm{H}$ shows that perceptions of electorate
}

combine the two measures, I dichotomized public support. ${ }^{9}$ Perceptual Accuracy takes the value of 1 if an individual MP correctly identifies the majority opinion among party voters, and 0 otherwise. ${ }^{10}$

The average value of Perceptual Accuracy is 0.73 . From 1985 to 2006, Swedish MPs correctly perceived the majority opinion in their party constituency $73 \%$ of the time. To provide a more detailed description of the variable, Figure 1 plots average values of perceptual accuracy by issue (gray lines) and for all issues asked in a given year (green line). Two patterns are worth noting. First, although perceptual accuracy is generally high, there is considerable variation across issues and over time. While $92 \%$ of MPs correctly perceived the majority opinion on the expansion of privately run health care in 2006 , over $60 \%$ of representatives misperceived voters' opinion on whether to decrease defense spending in the same year. Second, there is a gradual decline in perceptual accuracy over the two decades covered. Because this pattern may be simply due to the type of issues asked in each wave, Figure 1 also plots averages for the five issues that were asked consistently from 1985 to 2006 (orange line). The same general pattern is observed for this constant set of issues. Average perceptual accuracy among common issues went from $78.2 \%$ in 1985 to $65.4 \%$ in 2006 . It is beyond the scope of this project to explain this pattern. Still, it suggests that the ability of elected officials to gauge constituency preferences is dynamic.

The MP survey asked legislators about the preferences of their party constituency: voters who supported their party in the most recent election (2-4 months earlier). In performing this task, it is possible that politicians thought about different party supporters such as party members (Dalton 1985; Scarrow and Gezgor 2010; but see van Biezen and Poguntke 2014). While this could be consistent with the exposure hypothesis, it is important to note that in Sweden "party members resemble party voters to

preferences among Congressional staffers are also swayed by highstatus voters and egocentric biases. Together, the results suggest that the theoretical arguments advanced here are not contingent on the definition of constituency adopted.

${ }^{9}$ Majority support takes the value of 1 if over $50 \%$ of party respondents stated that a policy proposal was "very good" or "fairly good", and 0 otherwise. Voters without an opinion on a given policy are proportionately distributed among supporters and opponents. However, the same results are obtained when the share of supporters is calculated with undecided respondents in the denominator (Table C5) or when taking into account gradations of accuracy based on the distribution of constituency preferences (Table C6).

${ }^{10}$ A potential concern with this empirical approach is that once the mass public samples are split into party constituencies, we can no longer ensure that the average levels of policy support for each party are representative. Given the large sample sizes (see fn. 7) and the relatively small number of subgroups (seven parties), the magnitude of the biases resulting from disaggregating the sample is potentially limited. Still, I reestimated the main models with bootstrapped standard errors to incorporate uncertainty from the public opinion estimates. The same patterns are uncovered (see Table C7). The results are also robust to analyses considering only MPs from smaller parties, for whom the estimates of partisan policy support may be more prone to measurement error due to smaller sample sizes (see Table C8). 


\section{FIGURE 1. Average Perceptual Accuracy by Wave of Parliamentary Survey}

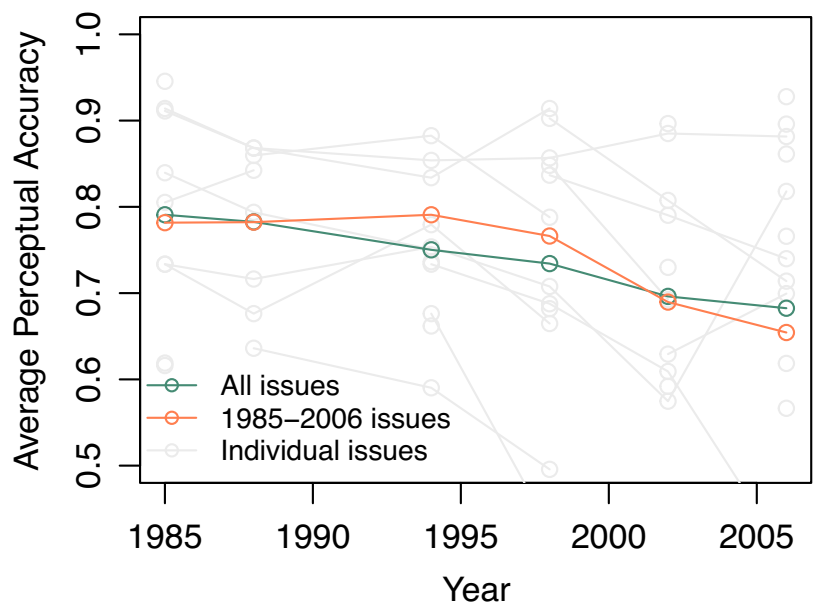

Note: "All issues" includes data from all 24 policy issues asked in the different waves; "1985-2006 issues" includes issues asked in at least five of the six waves, including 1985 and 2006: reduce public sector, reduce defense spending, more private health care, prohibit all kinds of pornography, and the introduction of six-hour working days.

a high degree. [...] Nordic parties have maintained a high level of representativeness when looking at the social composition of their membership" (Heidar et al. 2019, 93). Polk and Kölln (2019), in turn, report high levels of within-party congruence among party members, party voters, and party candidates in Sweden. This is likely due to the high levels of turnout in Swedish elections, between $80 \%$ and $90 \%$ in the period covered. In this context, thinking about different types of party constituencies-sympathizers, voters, or members-is unlikely to bias the results in a relevant way.

\section{Research Design}

If exposure shapes perceptions of constituency preferences, as articulated above, elected officials should give disproportionate weight to the preferences of highstatus voters. High-status voters are segments of the constituency with more political resources. These resources affect the ability of voters to make their voices heard in the policy-making process (e.g., Schlozman, Verba, and Brady 2012) and can be materialized in different ways: actual financial resources, organizational capacity, or accessibility to legislators (from common social networks or geographical proximity). To capture the multidimensional nature of high-status voters, I use four complementary variables: occupational social class, education, income, and place of residency. Social class is simultaneously a strong indicator of political resources and a meaningful political cleavage for both voters and politicians (Carnes and Lupu 2015; Evans 2000). Income and education, on the other hand, capture more directly individual resources and political influence. Finally, place of residence captures connectedness and access to the political sphere more broadly (Busch and Reinhardt 2005; Tavits 2005). Descriptive statistics for all variables included in the analysis are described in Appendix B.
To produce measures of policy support for different subconstituencies, I recoded each variable as follows. Occupational social class was split into three categories: blue-collar $(40.6 \%)$, white-collar $(42.3 \%)$, or other. Educational attainment was classified as low (1-9 grades or less; $31.4 \%$ ), medium (above comprehensive school but no college; $39.6 \%$ ), or high (college degree; $30.0 \%$ ). The measure of income is based on a distributional scale of household income validated by the Swedish register. From the original variable, I created three categories: low income (15th income percentile or lower), high income (85th percentile or higher), and medium income for the remaining subjects. Finally, place of residence is divided in two categories: respondents from rural areas and villages $(42.4 \%)$ and respondents from cities $(57.6 \%))^{11}$

Based on these typologies, I recalculated policy support exclusively among high-status partisans: (1) whitecollar, (2) high education, (3) high income, or (4) urban party voters. Finally, for each policy item I created a binary variable capturing opinion disagreement between high-status party constituents and the majority of copartisans. ${ }^{12}$ This process leads to four complementary predictors: one per measure of high status. As an example, consider the case where high status is captured through social class. The variable takes the value of 1 for a given MP from party $X$ if white-collar copartisans disagree with the majority of party $X$ voters on a given policy issue, and 0 otherwise. According to the exposure hypothesis, legislators are more likely to misperceive

\footnotetext{
${ }^{11}$ Table B2 describes the bivariate correlations between the different variables. Although all four variables are positively associated, correlations are moderate to small (Pearson's $r$ between 0.08 and 0.35 ). This suggests that the variables indeed capture different types of political resources.

12 The majority includes all party constituents regardless of levels of affluence.
} 


\section{FIGURE 2. Share of Policies Where MP Perceptions of Majority Preferences Align with High-status/ Low-status Voter Preferences}

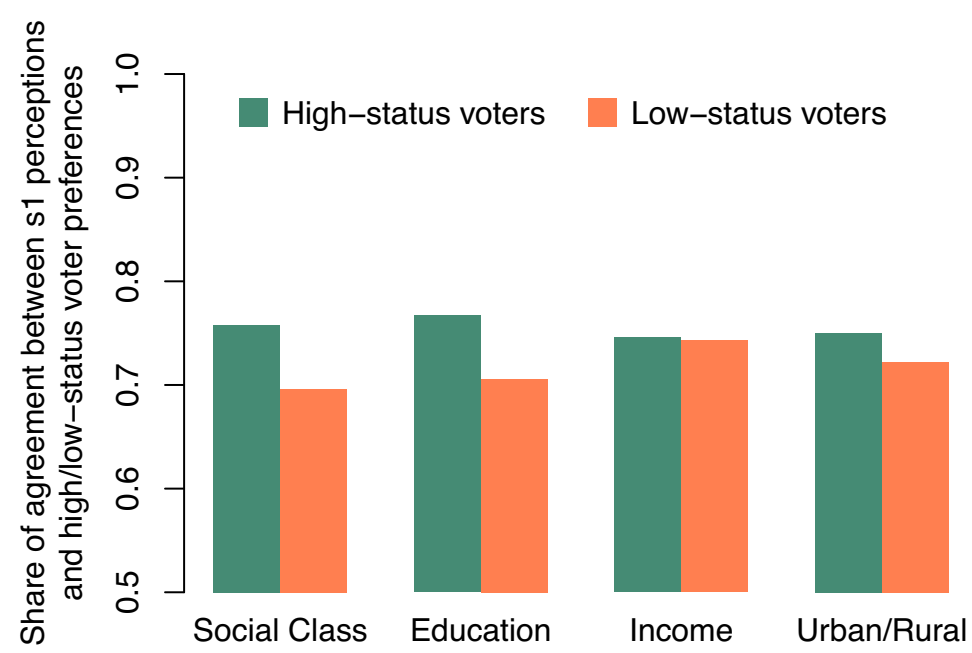

Note: Each bar represents the share of policy assessments in the parliamentary survey where MP perceptions of constituency preferences aligned with the majority opinion among different operationalizations of high/low-status voters (described along the $x$-axis).

public preferences when the position of privileged subconstituencies deviates from the majority.

To capture the propensity for social projection, in turn, I contrast the self-reported preferences of MPs with constituency preferences on the same policy. $\mathrm{MP} \neq$ Majority is a binary variable that takes the value of 1 if an MP disagrees with the majority of party constituents (either supporting or opposing the policy), and 0 otherwise.

The distribution of constituency preferences is likely to affect both the key predictors of interest in the analysis and perceptual accuracy. Thus, all models account for preference imbalance: the absolute difference between the share of constituents supporting or opposing a given policy. Smaller values reflect a more balanced distribution of preferences, which should be associated with less perceptual accuracy. Additionally, the models account for two individual features of the MPs that may shape their capacity to gauge constituency preferences: policy expertise and experience in office. Expertise is based on committee membership. To create this measure, I matched each policy issue available in the dataset to one of the Riksdag committees in place during the respective term. Expertise takes the value of 1 if the MP belongs to the committee associated with a given policy, and 0 otherwise. Experience in office is captured by the logged number of terms in office.

The final dataset includes several sources of variation: across time, parties, policies, and individual MPs. I am interested in capturing individual-level variation in the capacity of MPs to gauge constituency preferences. Therefore, the models include fixed effects to account for any systematic differences across time, party, or policy. Finally, because each MP enters the dataset multiple times (once per policy issue in a given wave, and eventually across waves), all models include clusterrobust standard errors by individual MP. The same results are obtained when the models alternatively include fixed effects by individual MP (Table C3).

\section{Results}

As a starting point for the analysis, Figure 2 describes levels of alignment between perceptions of public opinion and the preferences of high-status and low-status voters. The $x$-axis describes how the different subconstituencies are measured in each pair of estimates. Perceptions of public opinion among Swedish legislators are consistently better aligned with the preferences of high-status voters. With the exception of income, the differences in agreement between high- and low-status constituents are distinguishable from zero at conventional levels ( $p$-values $<0.05)$ and range from 4 to 7 percentage points. This descriptive pattern provides initial evidence that elite beliefs disproportionately reflect the position of privileged groups.

Figure 3 reports the main results from Study 1 . The estimates for each of the key predictors (listed on the $y$ axis) were derived from linear probability models with Perceptual Accuracy as the outcome. The predictor High-status $\neq$ Majority captures instances where highstatus voters deviate from the majority opinion on a given policy issue. Each color represents a pair of estimates from a different model based on the measure of high-status voters adopted. The results provide support for the two main predictions derived from the theory and are robust across measures of political resources.

Disagreements between high-status voters and the majority of party constituents are associated with lower perceptual accuracy. The effects are substantively meaningful. As an example, when white-collar voters disagree with the majority on a given issue (top estimate), the probability that MPs correctly perceive majority preferences is 12 percentage points lower. Importantly, these 
FIGURE 3. The Role of High-status Voters and MP Personal Preferences in Perceptual Accuracy

High-status $\neq$ Majority
$M P \neq$ Majority

effects imply that legislators are replacing the position of the majority with the position of privileged subconstituencies. Consider an instance where the majority supports a policy but white-collar voters oppose it. In this case the predictor takes the value of 1 . The negative coefficient means that legislators are more likely to (incorrectly) claim that the majority opposes the policy when white-collar voters also oppose it. Thus, perceptions of majority preferences follow the position of high-status constituents.

A similar pattern is observed when high-education voters disagree with the majority (point estimate = $-0.11 ; \mathrm{SE}=0.01$ ). Occupational social class and educational attainment are positively correlated (Pearson's $r=$ 0.28 ), but only $47.2 \%$ of self-identified white-collar respondents were also classified as high education. Therefore, the two constructs are not capturing the same subconstituency. Finally, the effects of policy disagreement for high-income voters are also statistically significant and in the expected direction, but they are smaller in magnitude (point estimate $=-0.04 ; \mathrm{SE}=0.01$ ). ${ }^{13}$

The models also provide support for the social projection hypothesis. Returning to the social class model (green estimates), the coefficient for $M P \neq$ Majority suggests that when MPs support/oppose a policy that is opposed/supported by the majority of party voters, the probability of correctly perceiving constituency preferences decreases 38 points. The estimated effects of social projection are sizeable. Holding the remaining variables at their medians, the predicted probability of correctly identifying the majority opinion on a given issue goes from 0.90 when MPs agree with their party

\footnotetext{
${ }^{13}$ As a robustness check, I reestimated the main models using gender as an indicator of high-status voters. Although Sweden is ranked among the most gender egalitarian countries in the world, important inequalities persist (Besley et al. 2017; Folke and Rickne 2020). Consistent with the exposure hypothesis, perceptual accuracy decreases when male constituents disagree with the majority. The same is not true for female constituents (Table C2).
}

constituency to 0.52 when MPs disagree. According to the model, the chances of dealigned MPs correctly perceiving copartisan preferences are close to those for a coin toss.

Importantly, these results are obtained accounting for preference imbalance within each party constituency. Opinion dealignment between voters and MPs is more likely when public opinion is evenly split on a given issue. However, all models account for the absolute difference between copartisan supporters and opponents in a given policy. The results are also not explained by time-invariant differences across legislators. As reported in Table C3, the same patterns are uncovered when the analyses include fixed effects by individual MP $(N=1,069)$.

A question that remains open is whether the effects of high-status voters disagreeing with the majority are unique to privileged groups. It is possible that the patterns observed mainly capture instances where the distribution of voter preferences is wider, or less crystallized. In this context, it is more likely (1) that some segments of the electorate have a distinct opinion from the majority and (2) that perceptual accuracy is lower, as gauging policy preferences can be more challenging. To assess this alternative explanation, I reestimated the main models replacing High-status $\neq$ Majority with measures of opinion disagreement between low-status voters and the majority. ${ }^{14}$ If the patterns observed above result from the lack of opinion crystallization, we should observe similar effects for privileged and less-privileged voters. The results reported in Figure C1 do not support this argument. Across specifications, the coefficient for disagreement between low-status voters

\footnotetext{
14 Low-status voters are identified as (1) blue-collar workers, (2) respondents with the ninth grade or less, (3) respondents in the 15 th income percentile or lower, or (4) respondents living in villages or rural areas.
} 
and the majority is either indistinguishable from zero or in the opposite direction of what we would expect. ${ }^{15}$

In sum, the analyses suggest that differential exposure and social projection are relevant drivers of elite misperceptions. When high-status voters disagree with the majority, legislators are systematically less likely to correctly gauge constituency preferences. The same is not true for low-status voters. In turn, when legislators themselves disagree with constituents on a given issue, their ability to identify the majority opinion is meaningfully curtailed.

\section{Mechanism Test: MP Behavior and Personal Background}

So far, the analysis suggests that Swedish MPs tend to rely disproportionately on the positions of high-status voters when gauging public opinion. This may be happening for a number of reasons. I argue that this pattern results from biases in exposure to different subconstituencies. ${ }^{16}$ If this mechanism is correct, we should expect the weight attached to the opinions of moreprivileged voters to vary according to (1) the active decisions of MPs to engage with different groups and (2) the idiosyncratic background of legislators.

To test the plausibility of this mechanism, I conducted two additional analyses. First, I reestimated the main model reported above, but conditioning White-collar $\neq$ Majority on how often MPs report meeting with (1) bluecollar unions (members of the Landsorganisationen $i$ Sverige) and (2) private businesses and business organizations. ${ }^{17}$ If the exposure hypothesis is correct, we should expect the capacity of white-collar preferences to sway elite perceptions of public opinion to decrease with the regularity of contacts with blue-collar unions. The opposite pattern would be expected for contacts with business organizations.

Figure 4 provides suggestive evidence in line with this argument. Panel (a) reports the marginal effects of white-collar voters disagreeing with the majority on a given issue, conditional on MPs' self-reported contacts with blue-collar unions. The distribution of the conditioning variable is described along the $x$-axis and

\footnotetext{
15 Table C11 provides an alternative modeling strategy to test the exposure hypothesis interacting high/low-status voter preferences with the size of the gap in preferences between subconstituencies. Consistent with the exposure hypothesis, only the effect of low-status preferences on elite perceptions decreases as the preference gap increases.

${ }^{16}$ An alternative mechanism is that legislators are actively giving more weight to the preferences of high-status voters with the expectation that this may help them in their reelection efforts (e.g., through donations) or in their postlegislative careers. The analyses conducted in this section only partially rule out this mechanism. However, the results in Study 2 are not consistent with this alternative story. If legislators were strategically misperceiving public opinion, encouraging them to develop more accurate perceptions of voter preferences should not lead to a decrease in misperceptions. This issue is further discussed in the concluding section.

${ }^{17}$ These variables are based on two items from the RDU surveys asking MPs how regularly they interacted personally, or by letter, with a variety of different organizations. Responses are recorded on a five-point labeled scale from "Never" to "At least once a week."
}

reveals appropriate common support for most of the scale. As expected, the weight of white-collar voter preferences is smaller among legislators with more exposure to blue-collar unions ( $p$-value for interaction term $=$ 0.05). According to the model, when white-collar voters disagree with the majority, the probability that an individual MP who never contacts blue-collar unions correctly identifies the majority position decreases 18.1 percentage points. The same effect for MPs who interact with unions once or twice a month decreases to 11.6 points. The opposite pattern is observed in Panel (b) for interactions with business organizations ( $p$-value $=0.08$ ). Regular contacts with businesses are associated with a heightened weight of white-collar preferences.

Next, I explore how the personal background of MPs can moderate exposure to different subconstituencies. I consider the role of MPs' (1) occupational class prior to joining parliament, (2) educational background, and (3) place of residence growing up. ${ }^{18}$ The expectation is that the preferences of high-status voters carry less weight among legislators with less-privileged backgrounds: non-white-collar MPs (53.1\% of the sample), MPs without a college degree $(43.1 \%)$, and MPs with a rural background $(51.4 \%)$.

The analyses reported in Figure 5 provide partial support for this prediction. Each panel reports the marginal effects of high-status voters disagreeing with the majority, conditional on MPs' (a) social class, (b) educational background, and (c) geographical background. The operationalization of high-status voters in each model matches the specific background feature of the MPs and is described on the $y$-axes. Across specifications, the results suggest that legislators with less-privileged backgrounds are less likely to rely on the positions of high-status voters when gauging constituency preferences. The effects are reliable for educational and geographical background. As an example, the estimates in panel (c) suggest that, when urban voters disagree with the majority, perceptual accuracy decreases on average 12.4 points among MPs with an urban background, but only 7.5 points among MPs with a rural background ( $p$-value of interaction term $=0.02)$. The results are consistent with research on the substantive effects of descriptive representation (Carnes and Lupu 2015).

Together, the analyses provide evidence for the mechanism underlying the exposure hypothesis. Both the behavior of MPs in office (Figure 4) and their idiosyncratic background (Figure 5) shape the type of information used when gauging constituency preferences.

\section{STUDY 2: EXPERIMENT WITH SWISS LOCAL OFFICIALS}

The previous study revealed two sources of bias in elite perceptions of public opinion: inequalities in exposure and social projection. I conducted Study 2 to assess

\footnotetext{
${ }^{18}$ The income levels of MPs are not available in the RDU surveys. However, I believe that the remaining measures properly capture the background of MPs.
} 


\section{FIGURE 4. The Marginal Effects of White-collar Voters Disagreeing with the Majority on Perceptual Accuracy Conditional on MP Contacts with Blue-collar Unions and Businesses}

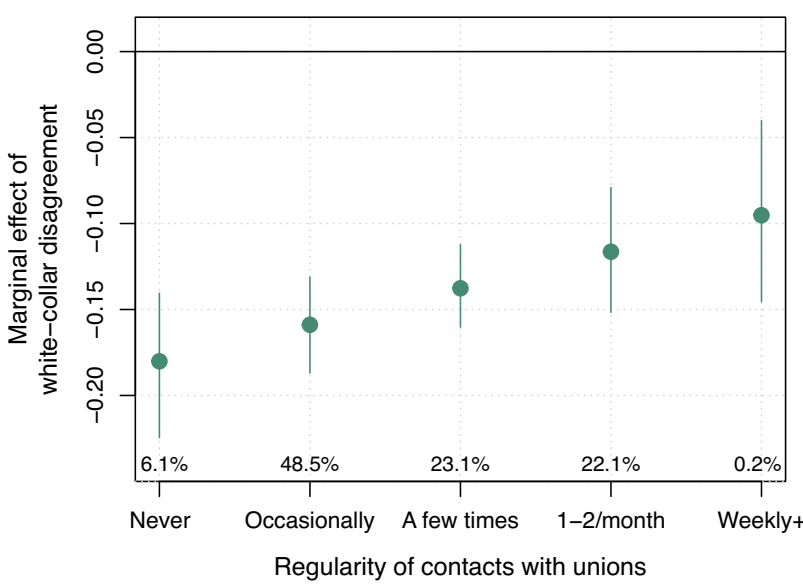

(a) White-collar weight by union contacts

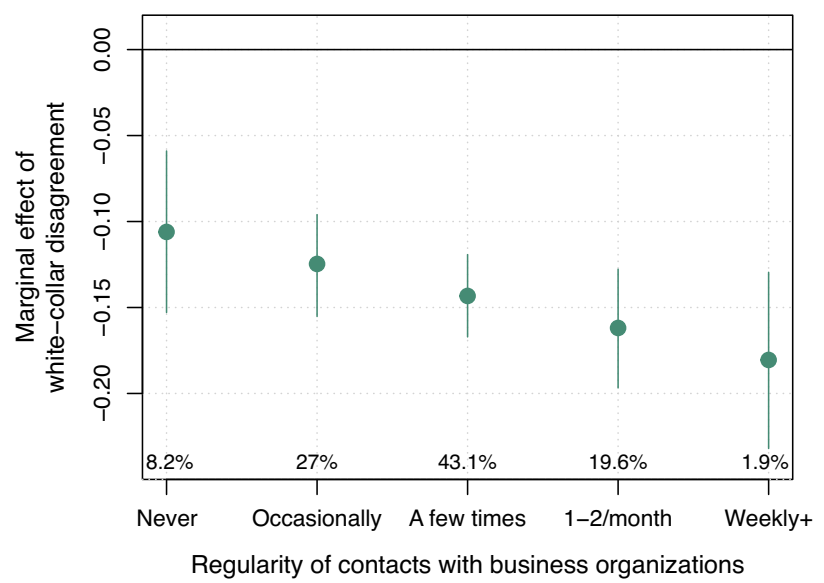

(b) White-collar weight by business contacts

Note: Dots are marginal effects of white-collar voters disagreeing with majority on perceptual accuracy, conditional on the regularity of contacts with blue-collar unions (panel a) and businesses (panel b). Vertical bars are $95 \%$ confidence intervals. Numbers along $x$-axis describe the distribution of the conditioning variable. See Table C9 for full results.

FIGURE 5. The Marginal Effects of High-status Voters Disagreement on Perceptual Accuracy Conditional on MPs' Class Background, Educational Background, and Geographical Background

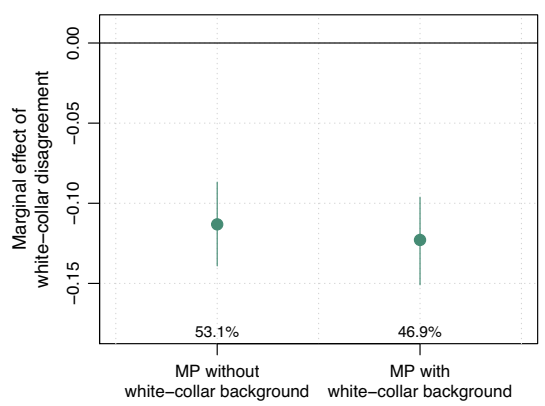

(a) Class background

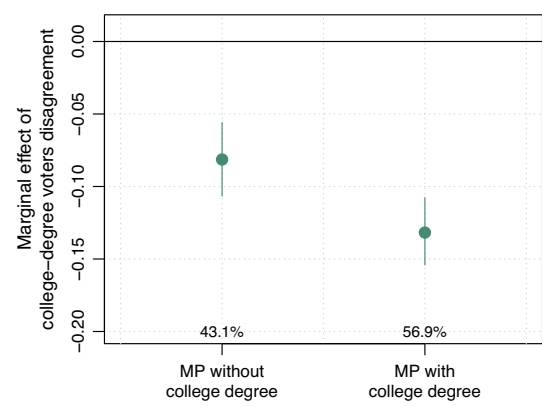

(b) Educational background

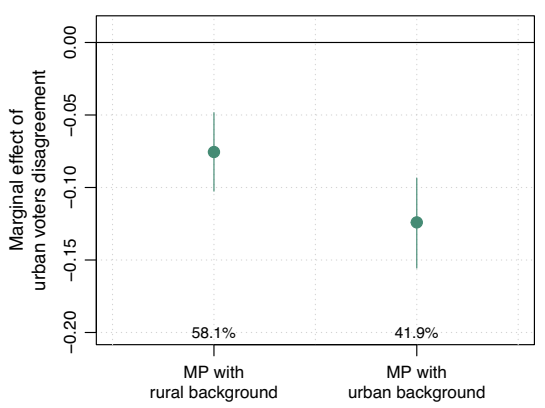

(c) Geographical background

Note: Dots are marginal effects of high-status voters disagreeing with majority on perceptual accuracy, conditional on the MP's class (panel a), educational (panel b), or geographical (panel c) background. The operationalization of high-status voters in each model is described along the $y$-axis and was chosen to be consistent with the moderator. Vertical bars are $95 \%$ confidence intervals. Numbers along the $x$-axis describe the distribution of the conditioning variable. See Table $\mathrm{C} 10$ for full results.

whether these biases can be minimized. Can public officials be encouraged to develop more accurate beliefs about their constituencies?

The analyses are based on an original survey of Swiss local elected officials leveraging real political events. Switzerland offers a unique opportunity to study elite perceptions of public opinion due to the large number of popular votes held every year. By conducting a survey of local representatives prior to a set of referendums, I was able to compare elite perceptions of constituency support for different issues with accurate behavioral measures of policy support at the municipal level. ${ }^{19}$ Two

\footnotetext{
${ }^{19}$ I use the terms "referendum" and "initiative" interchangeably. However, in Switzerland there is distinction between initiatives
}

advantages result from this empirical strategy. First, it allows me to go around measurement issues associated with calculating preferences for subnational constituencies. Second, as voter preferences are measured through referendum outcomes and politicians were asked to anticipate these same results, evidence for the exposure hypothesis cannot be explained by officials deliberately discounting the position of less-privileged subconstituencies because they are less likely to vote. Considerations about who turns out are embedded in the task.

(proposals initiated by citizens) and referendums (mandatory or optional). The two specific issues included in this study are popular initiatives. 
I recruited public officials as part of the 2017 National Survey of Local Executive Members (NSLEM), a large survey covering roughly $60 \%$ of the population of Swiss local elected officials (Steiner et al. 2019). ${ }^{20} \mathrm{~A}$ total of 5,240 participants provided their contact information to take part in a follow-up study. From this pool, 2,917 officials completed the online survey administered through Qualtrics (56.7\% response rate). ${ }^{21}$

The survey was fielded in November 2018, two weeks before a set of federal referendums. ${ }^{22}$ The questionnaire and all communication materials were translated to Swiss German, Swiss French, and Swiss Italian. ${ }^{23}$ The key goal of the survey was to capture elite perceptions of local public support for a series of popular initiatives voted on that occasion. Respondents were asked to predict the share of voters in their constituency who would support two distinct referendums: the selfdetermination initiative and the horned-cow initiative. The first referendum, initiated by the nationalist Swiss People's Party (SVP), proposed an amendment to the constitution that would give primacy to the Swiss constitution and popular votes over international treaties. The issue attracted substantial public attention and reached record levels in campaign spending (up to CHF 8 million, or $\$ 8 \mathrm{M}) .^{24}$ The horned-cow initiative, on the other hand, was a low-salience issue. The proposal sought to prevent farmers, through federal subsidies, from opting to keep hornless animals (Milic, Feller, and Küb 2019).

\section{Experimental Design}

Respondents were asked to predict the share of voters in their constituency who would support each referendum. ${ }^{25}$ Prior to the prediction tasks, officials were randomly assigned to one of three groups. ${ }^{26} \mathrm{~A}$ control group received no additional information. After reading a description of each referendum, officials in this group were directly asked to anticipate the outcome of the popular vote in their municipality. Two other groups

\footnotetext{
${ }^{20}$ More information available at: https://www.ipm.swiss/gemeinde/.

21 Table E1 summarizes the demographic characteristics of the sample and compares it with the 2017 NSLEM. There are no meaningful differences across the two samples in terms of individual characteristics of the subjects or sociopolitical features of the municipalities represented in each sample.

${ }^{22}$ The median local official completed the survey in the first two days, and $75 \%$ by the fifth day since the invitations were sent. Still, there is some variation in the timing of survey completion that could affect their capacity to gauge voter preferences. Table F3 shows that the timing between survey completion and the referendums did not affect the study results in a meaningful way.

23 An English translation of the questionnaire is provided in Appendix G, along with the informed consent.

${ }^{24}$ https://www.swissinfo.ch/eng/vote-november-25-2018_hotlydebated-swiss-law-first-initiative-awaits-public-verdict/44559238.

${ }^{25}$ In Switzerland, nationally representative polls are regularly published in the weeks leading to referendums. However, these polls do not provide municipal-level estimates. Therefore, local officials could not simply rely on existing survey data.

${ }^{26}$ The main hypotheses of the study were preregistered in EGAP: http://egap.org/registration/5322.
}

were presented with vignettes designed to increase perceptual accuracy, based on my theoretical predictions.

Exposure condition: This group received information about the composition of the electorate in their municipality. The goal of this intervention was to encourage local officials to avoid potentially skewed availability heuristics resulting from inequalities in exposure. To do so, respondents took part in a threestage task. First, they were asked to guess the prevalence of different segments of the electorate in their constituency (e.g., foreign-born citizens, supporters of the Green party). This information was recorded and reported on the following page of the survey along with the official data from the Federal Statistical Office for their municipality and for Switzerland as a whole. Finally, officials were asked to take this information into account when making their referendum predictions. Figure E1 provides a specific example of the vignette.

The type of information provided varied according to the referendum. To ensure that this information was informative, pretests assessed the predictive power of different indicators on support for similar referendums voted in the recent past. ${ }^{27}$ For the self-determination initiative, officials were presented with data on the share of foreign-born citizens and SVP voters in their municipality. For the horned-cow initiative, the information provided was the combined share of SP and Green party supporters in the constituency and the share of workers in the primary sector.

Exposure and Self-awareness Condition: The third group received the same informational treatment provided to the second group plus a recommendation to avoid projecting their own preferences on constituents. Box 1 provides the exact wording of the vignette. Recent scholarship suggests this type of feedback is the most effective way to mitigate social projection (Morewedge et al. 2015).28

The expectation is that officials in the exposure condition should be more likely to correctly perceive the majority opinion in their constituency relative to officials in the control condition. In turn, subjects who received the self-awareness intervention should be less likely to project their preferences on constituents and more likely to correctly perceive majority preferences (relative to the second group). To avoid contagion effects, randomization was made at the respondent level and the order of the referendums was randomized. Finally, I used multivariate continuous blocking to maximize balance between conditions on (1) partisanship, (2) language (German, French, or Italian), (3) municipality size (population), (4) canton, and (5) local support for the SVP and the Social Democratic Party (SP) in the previous general election. Table E2 reports covariate balance tests.

\footnotetext{
${ }^{27}$ Interviews with Swiss direct democracy scholars and preanalyses of VOTO, the postreferendum surveys (Milic, Feller, and Küb 2019), informed the selection of past referendums used for the pretests.

${ }^{28}$ I favored a cumulative treatments design over a full factorial design to maximize statistical power. To my knowledge, Swiss local officials had never been invited to an academic online survey before, so it was impossible to anticipate the sample size that would be obtained.
} 


\section{Box 1. Self-awareness Vignette}

Decades of research show that people tend to project their own preferences to others. Without noticing, we often overestimate approval for issues we support, while underestimating approval for issues we oppose. Try to take this into account when making your prediction.

\section{Results}

On November 25th, 2018, Swiss voters rejected both initiatives. Nationwide, $33.8 \%$ of voters supported the self-determination initiative, whereas $45.3 \%$ supported the horned-cow initiative. However, there was considerable variation across municipalities. Local support for the self-determination initiative, for instance, ranged from $12.5 \%$ to $83.7 \%$. Figure E2 describes the distributions of local-level support for each referendum.

I combined these expressed preferences with the survey results to build a measure of Perceptual Accur$a c y$. The variable takes the value of 1 if a local official correctly perceived the majority position in his or her constituency, for a given initiative, and 0 otherwise. ${ }^{29}$ On average, Swiss local officials correctly identified the majority position in their constituency $72 \%$ of the time. ${ }^{30}$ This figure represents a relatively high baseline, potentially resulting from the small size of Swiss local constituencies and the wealth of information provided to public officials by the regular referendums.

However, the interventions improved perceptual accuracy upon this baseline. Figure 6 presents the results of three linear probability models with Perceptual Accuracy as the outcome variable. Coefficients for each treatment condition (described along the $y$-axes) represent the average difference in the probability of correctly perceiving local majority support relative to the control group. ${ }^{31}$ Panel $a$ (from Figure 6) reports treatment effects for the self-determination initiative. On average, local officials who received information on electorate composition (the exposure group) were 6.4 percentage points more likely to correctly identify the majority position in their constituency relative to the control group. This effect is statistically significant $(p$-value $=0.002)$ and substantively meaningful. It

\footnotetext{
${ }^{29}$ I relied on a binary outcome for two reasons. First, I believe it better captures the key goal of grasping constituency preferences. While it might be helpful for elected officials to know the precise share of voters supporting a given policy, most models of representation mainly expect representatives to know the majority opinion in their constituency (Downs 1957; Katz 2014; Pitkin 1967). Second, this measure is consistent with the outcome variable used in Study 1 (Figure 3, above). The results for each initiative are substantively similar when an absolute measure of misperceptions is used instead (Figure F1).

30 The average values for the self-determination and horned-cow initiatives are 0.71 and 0.74 , respectively.

${ }^{31}$ Table F4 replicates these models with the subset of respondents who passed the manipulation check at the end of the survey. The same results are obtained, and the magnitude of the effects increases, overall.
}

represents an $8.9 \%$ increase in perceptual accuracy, relative to the mean value of the outcome. ${ }^{32}$ This pattern is in line with theoretical predictions. When representatives are encouraged to avoid availability heuristics and consider their constituency more broadly, perceptual accuracy increases. The effect of the Exposure and Self-awareness intervention, in turn, is also positive and reliable (point estimate $=0.04 ; p$ value $=0.04$ ). However, the effect is indistinguishable from the Exposure condition ( $p$-value $=0.31$ ). The analysis provides no evidence that encouraging political elites to avoid social projection increases perceptual accuracy.

The results for the horned-cow initiative (Panel b) are less conclusive. The estimates for Exposure (0.03) and Exposure and Self-awareness (0.02) are positive, as expected. However, the differences in the probability of correctly perceiving majority support are indistinguishable from zero at conventional levels of statistical significance. The analysis does not allow me to rule out small differences. Still, if anything, the treatment effects for this initiative were fairly small. ${ }^{33}$ Finally, Panel $c$ presents the pooled treatment effects on perceptual accuracy. This analysis includes fixed effects by initiative to account for any systematic differences between referendums and cluster-robust standard errors by local official. The results are consistent with the patterns observed for the self-determination initiative. The average differences in perceptual accuracy for officials in the Exposure and Exposure and Self-awareness conditions are $0.05(\mathrm{SE}=0.01)$ and $0.03(\mathrm{SE}=0.01)$, respectively.

Together, the results show that the exposure intervention effectively increased perceptual accuracy. However, the manipulation designed to encourage legislators to avoid social projection did not meaningfully alter how elected officials gauged public opinion. On average, officials who received the self-awareness vignette were not more likely to correctly perceive the majority opinion. This result is consistent with previous failed efforts to mitigate social projection in different contexts through perspective taking or feedback (Krueger and Clement 1994).

A question that remains open is whether the selfawareness intervention shaped the propensity of local officials to project their own preferences on constituents. To test this intermediate step, Figure 7 shows the results of linear models predicting perceived public support as a function of personal support (binary), interacted with the Exposure and Self-awareness condition. The models omit officials in the control group to isolate the effect of the self-awareness intervention by comparing the two treatment groups directly. The estimates in each panel are the coefficients of legislator support on perceived public support, for respondents in each treatment group (described in the $y$-axes).

\footnotetext{
32 The average value of Perceptual Accuracy for the selfdetermination initiative was 0.72 . Thus: $(0.064 / 0.72) \times 100=8.9 \%$.

${ }^{33}$ Formally exploring treatment heterogeneity by issue salience is beyond the scope of this study. However, it is possible that the lower salience associated with the horned-cow initiative may explain these results.
} 


\section{FIGURE 6. The Causal Effects of Exposure and Self-awareness of Social Projection on Perceptual Accuracy, by Referendum}

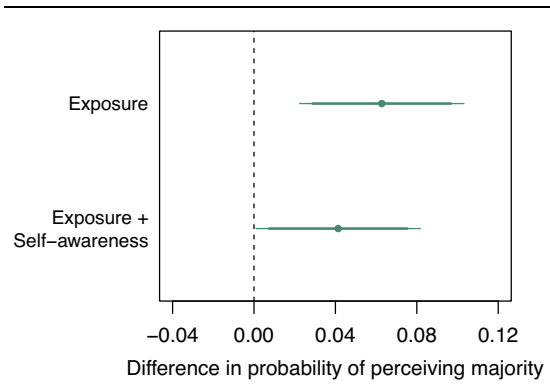

(a) Self-determination initiative

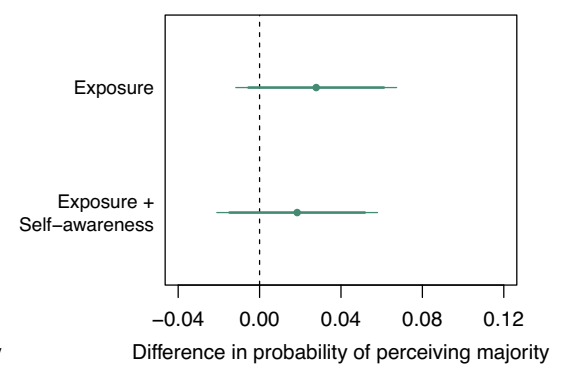

(b) Horned-Cow initiative

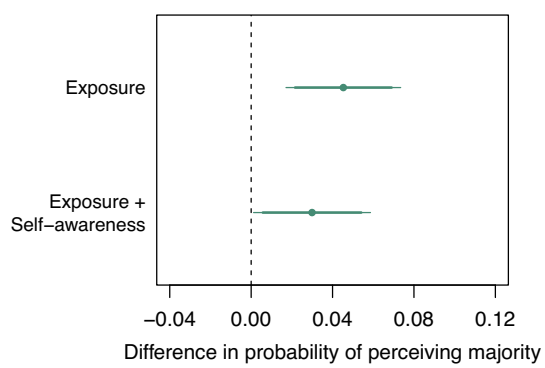

(c) Pooled initiatives

Note: Points are estimates of the difference in the probability of local officials correctly perceiving the majority opinion in their constituency by treatment condition (control = baseline and treatment groups described in the row labels). Wider/thinner horizontal lines are $95 \%$ and $90 \%$ confidence intervals. See Table F1 for full results.

\section{FIGURE 7. The Effects of Self-awareness on the Propensity of Legislators to Project Their Preferences on the Electorate, by Referendum}

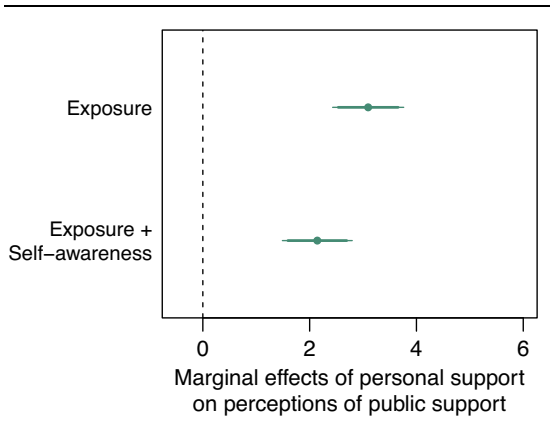

(a) Self-Determination initiative

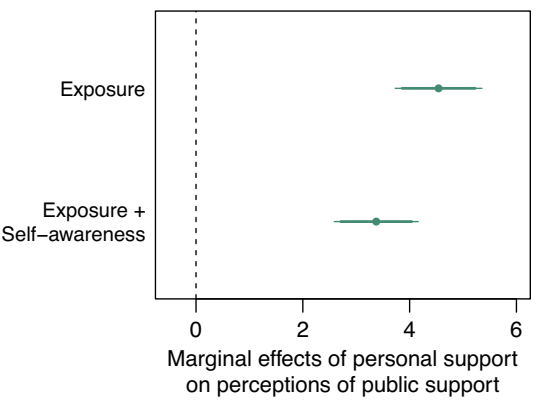

(b) Horned-Cow initiative

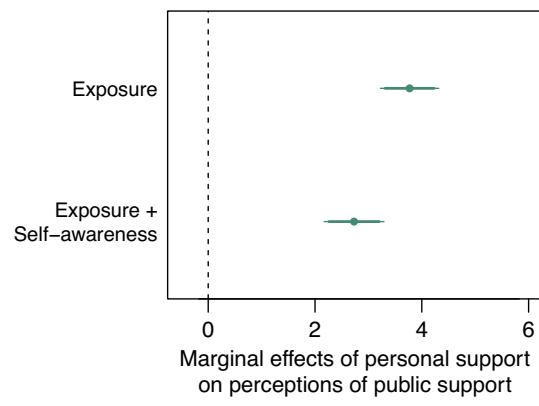

(c) Pooled initiatives

Note: Points are estimates of the effect of policy support on perceptions of public support, by treatment group (described in the row labels). Wider/thinner horizontal lines are $90 \%$ and $95 \%$ confidence intervals. Control group omitted from the analysis to isolate the effect of the selfawareness intervention. Full model results in Table F2.

Representatives in both conditions engaged in some degree of social projection. Regardless of treatment condition, the point estimates are positive and reliable. Legislators who supported a given issue perceived public support for that issue to be systematically higher.

However, subjects who received the self-awareness vignette were significantly less likely to project their own preferences on voters. The differences in point estimates are reliable in all specifications at conventional levels of statistical significance ( $p$-values of 0.046 , 0.04 , and 0.005 , respectively). The intervention reduced the propensity of legislators to project their preferences on voters, but this incentive was not enough to improve their ability to correctly identify the majority opinion. A potential explanation for this result is that social projection only translates into misperceptions when officials disagree with voters, and roughly two thirds of local officials in the study sided with the majority of their constituency in each issue. An alternative explanation is that the combined intervention was too demanding and encouraged satisficing.

\section{DISCUSSION}

This project explores how elected officials build their image of the constituency. I argue that inequalities in political voice and personal biases of elected officials play an important role in explaining misperceptions. Consistent with these arguments, Study 1 shows that Swedish MPs rely disproportionately on the positions of privileged subconstituencies. A propensity for legislators to overestimate support for policies they themselves endorse is also a powerful predictor of misperceptions. Next, I explore the degree to which these biases can be experimentally reduced. In a survey with nearly 3,000 Swiss local officials, respondents were asked to anticipate the outcome of two federal referendums in their constituency after being assigned to different informational nudges. The results show that misperceptions can be reduced by encouraging representatives to avoid inequalities in exposure.

The Swedish and Swiss studies were designed to complement each other. For instance, Study 1 allows 
for the possibility that politicians misperceive constituency preferences simply for strategic reasons: either because some groups matter more for reelection or because politicians derive utility from appearing in line with voters (halo effects). However, if this was the case, the informational cues in Study 2 should not affect perceptual accuracy. The Swiss study allows me to conclude that strategic considerations cannot fully account for the patterns observed.

Still, there are specific limitations that are important to emphasize. First, in Study 1 it is not possible to ensure that the measures of party constituency preferences are representative. The robustness of the findings among smaller parties, the electorate as a whole in 1985, and accounting for uncertainty in public opinion estimates mitigate these concerns. Still, more flexible measurement models that allow subsampling based on different political dimensions would represent a major contribution to the literature. What best represents a constituency for legislators in different European countries also remains an open question. In Study 1, party voters were defined as the key constituency for Swedish legislators, whereas in Switzerland the reference constituency was the group of voters who turned out in the referendums. The consistent results across studies, as well as in the United States (see Appendix H), suggest that the sources of misperceptions identified here may operate in similar ways regardless of how a constituency is defined. Still, how constituencies are defined in the eyes of representatives in different contexts remains an open question. Relatedly, the study builds upon a model of representation where all opinions in the constituency are weighed equally (Katz 2014). However, politicians may care less about voter preferences over policy and more about issue salience, policy outcomes, or the groups most affected by a given policy. Future contributions would benefit from exploring the implications of inequalities in exposure and egocentric biases in different models of representation.

The findings have several implications for the study of political representation and elite behavior. On one hand, the study reveals one way through which inequalities in political voice constrain the prospects of democratic representation. The study joins recent work in the United States uncovering relevant distortions in elite perceptions of public opinion (Broockman and Skovron 2018; HertelFernandez, Mildenberger, and Stokes 2019). However, Sweden and Switzerland are two of the most socially inclusive societies in the world. The fact that in both countries inequalities in political voice seem to have such meaningful effects on elite perceptions of public opinion is concerning. The findings shed some light on the path yet to cover until societies are able to sustain fully inclusive institutions. On the other hand, the Swiss study suggests that misperceptions are not unsurmountable. Encouraging legislators to avoid availability heuristics induced more accurate beliefs about voters. Although more research is needed to confirm the robustness of these findings, they suggest that improving perceptions of public opinion is possible even with subtle interventions.

The findings also contribute to scholarship on descriptive representation. Recent work shows how the social and professional backgrounds of politicians shape their behavior in office, even in party-centric systems (Carnes 2013; Carnes and Lupu 2015). The patterns reported here provide two novel explanations for this relationship. First, politicians with less-privileged backgrounds can be less susceptible to inequalities in exposure. Second, to the extent that shared backgrounds are associated with shared preferences, social projection can lead legislators to overestimate support for different policies, according to their individual milieu. Either mechanism can shape perceptions of public opinion without the active awareness of legislators, pushing them to pursue different policies while in office.

Finally, the Swiss experiment has the potential to pave the ground for new behavioral research with political elites. So far, this nascent area of research has focused on uncovering biases in elite behavior: instances where the decisions of legislators deviate from rational choice predictions (Esaiasson and Öhberg 2020; Sheffer et al. 2018) or from normative understandings of the democratic process (Costa 2017; Kalla and Broockman 2016; Pereira 2021a). A natural next step is to use this information to provide tools for elected officials to overcome those biases, as the Swiss experiment exemplifies. The results reveal how theory-driven interventions can encourage politicians to develop more accurate beliefs about their constituents. These findings are likely context- and design-dependent. Kalla and Porter (2020) provide less optimistic findings among state legislators in the United States. Future research should further investigate when and why elected officials are willing to update their beliefs about mass preferences.

\section{SUPPLEMENTARY MATERIALS}

To view supplementary material for this article, please visit http://dx.doi.org/10.1017/S000305542100037X.

\section{DATA AVAILABILITY STATEMENT}

Research documentation and data that support the findings of this study are openly available at the American Political Science Review Dataverse: https://doi. org/10.7910/DVN/HKV6YX.

\section{ACKNOWLEDGMENTS}

I would like to thank Daniel Butler, Nick Carnes, Christina Casnellie, Matthew Gabel, Nathalie Giger, Jonathan Homola, Jae-Hee Jung, Jeong Hyun Kim, David Miller, Andrew Stone, Margit Tavits, Dalston Ward, and Jeffrey Ziegler. Also thank you to Marc Bühlmann, Peter Esaiasson, Andreas Ladner, Lucas Leemann, Jan Fivaz, Julien Fiechter, Beat Furrer, Elin Naurin, Nicolas Pekari, Mikael Persson, and Patrik Öhberg, for the insights into Swedish and Swiss politics. This work was supported by APSA Centennial Center, and Washington University's Graduate Research Seed Grant. 


\section{CONFLICT OF INTEREST}

The author declares no ethical issues or conflicts of interest in this research.

\section{ETHICAL STANDARDS}

The author declares that the human subjects research in this article was reviewed and approved by the Human Research Protection Office at Washington University in St. Louis (IRB protocol \#201810084) and the Ethics Commission at University of Geneva (CER-SDS-12-2018). The author affirms that this article adheres to the APSA's Principles and Guidance on Human Subject Research.

\section{REFERENCES}

Adams, James, and Lawrence Ezrow. 2009. "Who do European Parties Represent? How Western European Parties Represent the Policy Preferences of Opinion Leaders." The Journal of Politics 71 (1): 206-23.

Agostinelli, Gina, Steven J. Sherman, Clark C. Presson, and Laurie Chain. 1992. "Self-protection and Self-enhancement Biases in Estimates of Population Prevalence." Personality and Social Psychology Bulletin 18 (5): 631-42.

Ajzen, Icek. 1996. "The Social Psychology of Decision Making." In Social Psychology: Handbook of Basic Principles, eds. E. Tory Higgins and Arie W. Kruglanski, 297-325. New York: Guilford Press.

Bartels, Larry. 2008. Unequal Democracy: The Political Economy of the New Gilded Age. New York: Russell Sage Foundation and Princeton University Press.

Besley, Timothy, Olle Folke, Torsten Persson, and Johanna Rickne. 2017. "Gender Quotas and the Crisis of the Mediocre Man: Theory and Evidence from Sweden." American Economic Review 107 (8): 2204-42.

Binderkrantz, Anne Skorkjær, Peter Munk Christiansen, and Helene Helboe Pedersen. 2015. "Interest Group Access to the Bureaucracy, Parliament, and the Media." Governance 28 (1): 95-112.

Broockman, David E., and Christopher Skovron. 2018. "Bias in Perceptions of Public Opinion among Political Elites." American Political Science Review 112 (3): 542-63.

Busch, Marc L., and Eric Reinhardt. 2005. "Industrial Location and Voter Participation in Europe." British Journal of Political Science 35 (4): 713-30.

Butler, Daniel M. 2014. Representing the Advantaged: How Politicians Reinforce Inequality. New York: Cambridge University Press.

Butler, Daniel M., and David W. Nickerson. 2011. "Can Learning Constituency Opinion Affect How Legislators Vote? Results from a Field Experiment." Quarterly Journal of Political Science 6(1): 55-83.

Butler, Daniel M., and Adam M. Dynes. 2016. "How Politicians Discount the Opinions of Constituents with Whom They Disagree." American Journal of Political Science 60 (4): 975-89.

Campbell, David. 2013. "Social Networks and Political Participation." Annual Review of Political Science 16: 33-48.

Carlston, Donal E., and Eliot Smith. 1996. "Principles of Mental Representation." In Social Psychology: Handbook of Basic Principles, eds. E. Tory Higgins and Arie W. Kruglanski, 184-210. New York: Guilford Press.

Carnes, Nicholas. 2013. White-collar Government: The Hidden Role of Class in Economic Policy Making. Chicago: University of Chicago Press.

Carnes, Nicholas, and Noam Lupu. 2015. "Rethinking the Comparative Perspective on Class and Representation: Evidence from Latin America." American Journal of Political Science 59 (1): $1-18$.

Christensen, Julian, and Donald P. Moynihan. 2020. "Motivated

Reasoning and Policy Information: Politicians Are More Resistant to Debiasing Interventions Than the General Public." Behavioural Public Policy. doi:10.1017/bpp.2020.50.

Clement, Russell W., and Joachim Krueger. 2000. "The Primacy of Self-referent Information in Perceptions of Social Consensus." British Journal of Social Psychology 39 (2): 279-99.

Converse, Philip E., and Roy Pierce. 1986. Political Representation in France. Cambridge, MA: Harvard University Press.

Crosson, Jesse M., Alexander C. Furnas, and Geoffrey M. Lorenz. 2020. "Polarized Pluralism Organizational Preferences and Biases in the American Pressure System." American Political Science Review 114 (4): 1117-37.

Costa, Mia. 2017. "How Responsive Are Political Elites? A Metaanalysis of Experiments on Public Officials." Journal of Experimental Political Science 4 (3): 241-54.

Dal Bó, Ernesto, Frederico Finan, Olle Folke, Torsten Persson, and Johanna Rickne. 2019. "Economic Losers and Political Winners: Sweden's Radical Right.” Unpublished Manuscript. http:// perseus.iies.su.se/ tpers/papers/CompleteDraft190301.pdf.

Dalton, Russell J. 1985. "Political Parties and Political Representation: Party Supporters and Party Elites in Nine Nations." Comparative Political Studies 18 (3): 267-99.

Davis, Mark H. 2017. "Social Projection to Liked and Disliked Targets: The Role of Perceived Similarity." Journal of Experimental Social Psychology 70: 286-93.

Däubler, Thomas. 2020. "National Policy for Local Reasons: How MPs Represent Party and Geographical Constituency through Initiatives on Social Security." Acta Politica 55: 472-91.

Downs, Anthony. 1957. "An Economic Theory of Political Action in a Democracy." Journal of Political Economy 65 (2): 135-50.

Druckman, James N., and Lawrence R. Jacobs. 2015. Who Governs?. Presidents, Public Opinion, and Manipulation. Chicago: University of Chicago Press.

Epley, Nicholas, Boaz Keysar, Leaf Van Boven, and Thomas Gilovich. 2004. "Perspective Taking As Egocentric Anchoring and Adjustment." Journal of Personality and Social Psychology 87 (3): 327-39.

Erikson, Robert S., Norman R. Luttbeg, and William V. Holloway. 1975. "Knowing One's District: How Legislators Predict Referendum Voting." American Journal of Political Science 19 (2): 231-46.

Esaiasson, Peter, and Sören Holmberg. 1996. Representation from Above: Members of Parliament and Representative Democracy in Sweden. Aldershot, UK: Dartmouth.

Esaiasson, Peter, and Patrik Öhberg. 2020. "The Moment You Decide, You Divide: How Politicians Assess Procedural Fairness." European Journal of Political Research 59 (3): 714-30.

Evans, Geoffrey. 2000. "The Continued Significance of Class Voting." Annual Review of Political Science 3: 401-17.

Fiedler, Klaus, and Jeannette Schmid. 1995. "Heuristics." In The Blackwell Encyclopedia of Social Psychology, eds. Anthony Manstead and Miles Hewston, 296-300. Oxford: Blackwell Press.

Folke, Olle, and Johanna Rickne. 2020. "All the Single Ladies: Job Promotions and the Durability of Marriage." American Economic Journal: Applied Economics 12 (1): 260-87.

Gabel, Matthew, and Kenneth Scheve. 2007. "Estimating the Effect of Elite Communications on Public Opinion Using Instrumental Variables." American Journal of Political Science 51 (4): 1013-28.

Gallego, Aina. 2007. "Unequal Political Participation in Europe." International Journal of Sociology 37 (4): 10-25.

Galston, William A. 2001. "Political Knowledge, Political Engagement, and Civic Education." Annual Review of Political Science 4 (1): 217-34.

Geer, John Gray. 1996. From Tea Leaves to Opinion Polls: A Theory of Democratic Leadership. New York: Columbia University Press

Giger, Nathalie, Jan Rosset, and Julian Bernauer. 2012. "The Poor Political Representation of the Poor in a Comparative Perspective." Representation 48 (1): 47-61.

Giger, Nathalie, and Heike Klüver. 2016. "Voting against Your Constituents? How Lobbying Affects Representation.” American Journal of Political Science 60 (1): 190-205. 
Gilens, Martin. 2009. "Preference Gaps and Inequality in Representation." PS: Political Science \& Politics 42 (2): 335-41. Griffin, John, and Brian Newman. 2005. "Are Voters Better Represented?" The Journal of Politics 67 (4): 1206-27.

Gulzar, Saad, Zuhad Haai, and Binod Kumar Paudel. 2020. "Information, Candidate Selection, and Quality of Representation: Evidence from Nepal." The Journal of Politics https://doi.org/10.1086/711898.

Heidar, Knut, Gunnar Helgi Kristinnsson, Arttu Saarinen, Aki Koivula, and Teo Keipi. 2019. "Who Are the Party Members and Are They Representative of the Party Voters?" In Nordic Party Members: Linkages in Troubled Times, eds. Marie Demker, Knut Heidar, and Karina Kosiara-Pedersen, 75-96. London: Rowman \& Littlefield International/ECPR

Hertel-Fernandez, Alexander, Matto Mildenberger, and Leah C. Stokes. 2019. "Legislative Staff and Representation in Congress." American Political Science Review 113 (1): 1-18.

Holmberg, Sören. 1974. Riksdagen representerar svenska folket: empiriska studier i representativ demokrati. Gothenburg: University of Gothenburg Press.

Holmberg, Sören. 1989. "Political Representation in Sweden." Scandinavian Political Studies 12 (1): 1-36.

Holmberg, Sören. 1999. "Wishful Thinking among European Parliamentarians." In Political Representation and Legitimacy in the European Union, eds. Hermann Schmitt and Jacques Thomassen, 235-53. Oxford: Oxford University Press.

Homola, Jonathan. 2019. "Are Parties Equally Responsive to Women and Men?" British Journal of Political Science 49 (3): 957-75.

Kalla, Joshua L., and David E. Broockman. 2016. "Campaign Contributions Facilitate Access to Congressional Officials: A Randomized Field Experiment." American Journal of Political Science 60 (3): 545-58.

Kalla, Joshua L., and Ethan Porter. 2020. "Correcting Bias in Perceptions of Public Opinion among American Elected Officials: Results from Two Field Experiments.” British Journal of Political Science. doi:10.1017/S0007123419000711.

Karlsson, David, and Lukas Nordin. 2015. "Riksdagsundersökningen 2014." Paper presented at NorKom XXIII, Odense, Denmark. http://hdl.handle.net/2077/40653.

Katz, Daniel, and Floyd Henry Allport. 1931. Students' Attitudes: A Report of the Syracuse University Reaction Study. Syracuse, NY: Craftsman Press.

Katz, Richard S. 2014. "No Man Can Serve Two Masters: Party Politicians, Party Members, Citizens and Principal-Agent Models of Democracy." Party Politics 20 (2): 183-93.

Katz, Richard. 2020. "Party Government and Representation." In The Oxford Handbook of Political Representation in Liberal Democracies, eds. Robert Rohrschneider and Jacques Thomassen, 249-67. Oxford: Oxford University Press.

Kertzer, Joshua D., Joshua Busby, Jonathan Monten, Jordan Tama, and Craig Kafura. 2020. "Elite Misperceptions and the Domestic Politics of Conflict." Unpublished Manuscript. http:// people.fas.harvard.edu/ jkertzer/Research_files/NATOMisperceptions-Web.pdf.

Klüver, Heike. 2020. "Setting the Party Agenda: Interest Groups, Voters and Issue Attention." British Journal of Political Science 50 (3): 979-1000.

Krueger, Joachim, and Russell W. Clement. 1994. "The Truly False Consensus Effect: An Ineradicable and Egocentric Bias in Social Perception." Journal of Personality and Social Psychology 67 (4): 596-610.

Ladner, Andreas. 2005. "Laymen and Executives in Swiss Local Government." In Transforming Local Political Leadership, eds. Rikke Berg and Nirmala Rao, 101-15. Houndmills: Palgrave Macmillan.

Lax, Jeffrey R., Justin H. Phillips, and Adam Zelizer. 2019. "The Party or the Purse? Unequal Representation in the US Senate." American Political Science Review 113 (4): 917-40.

Liaqat, Asad. 2020. "No Representation without Information: Politician Responsiveness to Citizen Preferences.” Unpublished Manuscript. https://scholar.harvard.edu/files/asadliaqat/files/jmp.pdf.

Lloren, Anouk, Jan Rosset, and Reto Wüest. 2015. "Descriptive and Substantive Representation of Poor Citizens in Switzerland." Swiss Political Science Review 21 (2): 254-60.
Lodge, Milton, Patrick Stroh, and John Wahlke. 1990. "Black-box Models of Candidate Evaluation.” Political Behavior 12 (1): 5-18.

Lublin, David. 2018. "Five Lessons from the Mayor's Desk." PS. Political Science \& Politics 51 (1): 169-72.

Mendelberg, Tali, Katherine T. McCabe, and Adam Thal. 2017. "College Socialization and the Economic Views of Affluent Americans." American Journal of Political Science 61 (3): 606-23.

Miler, Kristina. 2007. "The View from the Hill: Legislative Perceptions of the District." Legislative Studies Quarterly 32 (4): 597-628.

Milic, Thomas, Alessandro Feller, and Daniel Küb. 2019. "Résumé de l'enquête VOTO relative à la votation populaire fédérale du 25 novembre 2018." ZDA, FORS, January 10, 2019. https:// www.voto.swiss/wp-content/uploads/2019/01/VOTO 25.11.2018_Summary_FR.pdf.

Miller, Warren E., and Donald E. Stokes. 1963. "Constituency Influence in Congress." American Political Science Review 57 (1): $45-56$.

Morewedge, Carey K., Haewon Yoon, Irene Scopelliti, Carl W. Symborski, James H. Korris, and Karim S. Kassam. 2015. "Debiasing Decisions: Improved Decision Making with a Single Training Intervention." Policy Insights from the Behavioral and Brain Sciences 2 (1): 129-40.

Mullen, Brian, Jennifer L. Atkins, Debbie S. Champion, Cecelia Edwards, Dana Hardy, John E. Story, and Mary Vanderklok. 1985. "The False Consensus Effect: A Meta-analysis of 115 Hypothesis Tests." Journal of Experimental Social Psychology 21 (3): 262-83.

Norris, Pippa, and Joni Lovenduski. 1995. Political Recruitment: Gender, Race and Class in the British Parliament. Cambridge: Cambridge University Press.

Öhberg, Patrik, and Elin Naurin. 2016. "Party-constrained Policy Responsiveness: A Survey Experiment on Politicians' Response to Citizen-initiated Contacts." British Journal of Political Science 46 (4): 785-97.

Olson, Mancur. 1965. The Logic of Collective Action: Public Goods and the Theory of Groups. Cambridge, MA: Harvard University Press.

Page, Benjamin I., and Robert Shapiro. 1984. "Presidents as Opinion Leaders: Some New Evidence.” Policy Studies Journal 12 (4): 649-61.

Pereira, Miguel M. 2019. "Do Parties Respond Strategically to Opinion Polls? Evidence from Campaign Statements." Electoral Studies 59: 78-86.

Pereira, Miguel M. 2020. "Responsive Campaigning: Evidence from European Parties." The Journal of Politics 82 (4): 1183-95.

Pereira, Miguel M. 2021a. "How Do Public Officials Learn about Policy? A Field Experiment on Policy Diffusion." British Journal of Political Science. doi:10.1017/S0007123420000770.

Pereira, Miguel M. 2021b. "Replication data for: Understanding and Reducing Biases in Elite Beliefs about the Electorate." Harvard Dataverse. Dataset. https://doi.org/10.7910/DVN/HKV6YX.

Persson, Mikael, and J. Alexander Branham. 2020. "From Opinions to Policies: Examining the Links between Citizens,

Representatives, and Political Decisions." Unpublished Manuscript.

Pitkin, Hanna F. 1967. The Concept of Representation. Berkeley: The University of California Press.

Polk, Jonathan, and Ann-Kristin Kölln. 2019. "Parties' Ideological Representation in the Nordic Countries: Comparing Party Voters, Members and Candidates" In Nordic Party Members: Linkages in Troubled Times, eds. Marie Demker, Knut Heidar, and Karina Kosiara-Pedersen, 97-110. London: Rowman \& Littlefield International.

Rehfeld, Andrew. 2005. The Concept of Constituency: Political Representation, Democratic Legitimacy, and Institutional Design. Cambridge: Cambridge University Press.

Ross, Lee, David Greene, and Pamela House. 1977. "The 'False Consensus Effect': An Egocentric Bias in Social Perception and Attribution Processes." Journal of Experimental Social Psychology 13 (3): 279-301.

Rueda, David, and Daniel Stegmueller. 2016. "The Externalities of Inequality: Fear of Crime and Preferences for Redistribution in Western Europe." American Journal of Political Science 60 (2): 472-89.

Scarrow, Susan E., and Burcu Gezgor. 2010. "Declining Memberships, Changing Members? European Political Party Members in a New Era." Party Politics 16 (6): 823-43. 
Schakel, Wouter. 2019. "Unequal Policy Responsiveness in the Netherlands." Socio-economic Review. https://doi.org/10.1093/ser/ mwz018.

Schattschneider, Elmer Eric. 1975. The Semisovereign People: A Realist's View of Democracy in America. Belmont, CA: Wadsworth Publishing Company.

Schlozman, Kay Lehman, Sidney Verba, and Henry E. Brady. 2012. The Unheavenly Chorus: Unequal Political Voice and the Broken Promise of American Democracy. Princeton, NJ: Princeton University Press.

Sheffer, Lior, Peter John Loewen, Stuart Soroka, Stefaan Walgrave, and Tamir Sheafer. 2018. "Nonrepresentative Representatives: An Experimental Study of the Decision Making of Elected Politicians." American Political Science Review 112 (2): 302-21.

Steiner, Reto, Andreas Ladner, Claire Kaiser, and Jana Machljankin. 2019. Survey of the Members of Swiss Local Governments, 2017. Winterthur/Lausanne: ZHAW/IDHEAP.

Strolovitch, Dara Z. 2008. Affirmative Advocacy: Race, Class, and Gender in Interest Group Politics. Chicago: University of Chicago Press.

Suhay, Elizabeth, Marko Klašnja, and Gonzalo Rivero. 2021. "Ideology of Affluence: Rich Americans' Explanations for Inequality and Attitudes toward Redistribution." The Journal of Politics 83 (1) 367-80.
Tavits, Margit. 2005. "The Development of Stable Party Support: Electoral Dynamics in Post-communist Europe." American Journal of Political Science 49 (2): 283-98.

The Robert Schuman Foundation. 2016. "Supporters and Adversaries to the UK Remaining in the European Union are Running Neck and Neck in the Polls Just One Month before the Referendum." European Elections Monitor, June 23. https:// www.robert-schuman.eu/en/doc/oee/oee-1647c-en.pdf.

Tversky, Amos, and Daniel Kahneman. 1974. "Judgment under Uncertainty: Heuristics and Biases." Science 185: 1124-31.

van Biezen, Ingrid, and Thomas Poguntke. 2014. "The Decline of Membership-based Politics.” Party Politics 20 (2): 205-16.

van Boven, Leaf, David Dunning, and George Loewenstein. 2000. "Egocentric Empathy Gaps between Owners and Buyers: Misperceptions of the Endowment Effect." Journal of Personality and Social Psychology 79 (1): 66-76.

Verba, Sidney, Kay Lehman Schlozman, and Henry E. Brady. 1995. Voice and Equality: Civic Voluntarism in American Politics. Cambridge, MA: Harvard University Press.

Voorheis, John, Nolan McCarty, and Boris Shor. 2015. Unequal Incomes, Ideology and Gridlock: How Rising Inequality Increases Political Polarization. Rochester, NY: Social Science Research Network. 